\title{
Os tóxicos dos alimentos
}

\section{1. - Introdução}

$\mathrm{Na}$ biosfera podemos conviver com mais de um centena de elementos, isto é, com tantos quantas foram as previsões de Mendeléeff. Com eles, a natureza, utilizando mais uns do que outros, fez arquitecturas moleculares maravilhosas em utilidade, deslumbrantes em beleza e algumas tenebrosas pelo perigo que encerram. Os químicos, na sua missão de colaboradores no plano da criação, por mimetismo com o natural e graças à força criadora da imaginação, saber e técnica, criaram, estão criando e continuarão a criar novas moléculas, enriquecendo continuamente $\mathrm{o}$ arsenal natural. A Indústria Química encarrega-se das suas preparações, divulgação e disseminação, daqui resultando que milhōes de moléculas, na forma de vida ou não, constituam o nosso habitat.

Com elas, de modo permanente e contínuo, vamos aprendendo a viver fazendo as adaptaçðes necessárias ou possíveis às exigências que vão surgindo e nos são reclamadas.

Apenas a vinte e sete desta centena de elementos é reconhecido o estatuto de "bioelemento". Destes, somente o oxigénio, o hidrogénio, o azoto, o carbono e mais dezojto ocupantes da tabela periódica, $9 \mathrm{~F}$, $11 \mathrm{Na}, 12 \mathrm{Mg}, 15 \mathrm{P}, 16 \mathrm{~S}, 17 \mathrm{Cl}, 19 \mathrm{~K}, 20 \mathrm{Ca}, 23 \mathrm{~V}, 24 \mathrm{Cr}$, $25 \mathrm{Mn}, 26 \mathrm{Fe}, 27 \mathrm{Co}, 29 \mathrm{Cu}, 30 \mathrm{Zn}, 34 \mathrm{Se}, 42 \mathrm{Mo}$, e $53 \mathrm{I}$ são considerados "essenciais" ao homem pela imprescindibilidade à sua fisiologia e desenvolvimento normal.

Alguns têm que ser ingeridos em formas muito particulares:

O H é necessário na forma de água,

O Co na forma de cianocobalamina (vitamina $B_{12}$ ) e

O S na de metionina, etc.

Todos estes elementos de que precisamos nos são garantidos pelos alimentos desde que ingeridos em quantidade satisfatória, de forma variada, adequada e harmónica.

A grande maioria dos milhares de compostos orgânicos participantes nos processos bioquímicos são sintetizados endogenamente, e tal só é possível a partir de um número mínimo de moléculas simples.

Pode resumir-se a vinte e cinco o número mínimo de substâncias orgânicas que nos são essenciais e que obrigatoriamente temos de ingerir "pré-formadas" nos alimentos:

-10 aminoácidos, geralmente ingeridos na forma de proteínas.

-13 vitaminas.

- Um ácido gordo dos considerados essenciais (linoleico, linolénico e araquidónico).
- Um hidrato de carbono assimilável em quantidade
impeditiva da cetose.

O homem vê-se confrontado com uma pleiade de elementos e compostos de que não precisa (ou julga não precisar) e irremediavelmente dependente de outros sem os quais não sobrevive. Vê-se obrigado a manter uma luta em duas frentes. Luta ao ataque e se preciso até à exaustão para conseguir os últimos e na defensiva contra os primeiros.

Não surpreende pois, que simultaneamente com os gemidos dos famintos e dos padecentes de malnutrição ouçamos as vozes de outros com "slogans" contra os "produtos químicos" contidos nos alimentos. E afinal todos têm razão.

De facto em todo o mundo, os desequilibrios alimentares constituem um dos mais importantes factores de risco para a saúde pública e não menos preocupante $\mathrm{e}$ gravoso do que o causado pelos compostos estranhos, indesejáveis e tóxicos dos alimentos. Não faz sentido mencionar os desequilíbrios que em matéria alimentar se cometem entre nós uma vez que a nossa proposta é abordar os tóxicos dos alimentos. Valeria a pena fazê-lo.

Voluntária ou involuntariamente é, por via oral, que o homem mais frequentemente se intoxica.

$\mathrm{O}$ tóxico e o alimento constituem um binómio íntimo e solidário, de difícil dissociação tal é a carga que os mantém unidos.

$\mathrm{O}$ alimento mais útil ao organismo pode tornar-se por si mesmo tóxico, sendo a sua utilidade ou toxicidade dependente do estado fiosiológico do indivíduo a quem ele se destina e da quantidade em que for ingerido. Os diabéticos têm que ingerir dietas hipoglucídicas, mais pobres em glúcidos do que as prescritas para indivíduos sãos, os hiperlipodémicos, dietas hipolipídicas, certos doentes renais dietas hipoproteicas, etc. sob pena de priorarem os seus estados. Alguns desses bioelementos têm de ser usados em quantidades reduzidas, havendo que respeitar uma correcta correlação entre eles sob pena de perderem a sua utilidade e passarem a ser deletérios.

As substâncias estranhas, aleloquímicas ou não nutritivas dos alimentos apenas se comportam como xenobióticos quando a quantidade ingerida, ou melhor, a quantidade absorvida ultrapassar o limiar da capacìdade do organismo para as suas destoxicaçðes.

A nutrição e a alimentação humana pauta-se por este equilibrio e balanceamento de risco e benefícios que os alimentos protagonizam.

\footnotetext{
a Laboratório de Bromatologia, Faculdade de Farmácia, Universidade do Porto.
} 


\section{2. - Os contaminantes dos alimentos e as suas toxicidades}

Os contaminantes, substâncias potencialmente tóxicas, aparecem pré-formadas ou não nos alimentos.

Têm origem natural, resultando da elaboração do metabolismo animal, vegetal e microbiano ou resultam da contaminação furtuita do alimento como consequência do ambiente aéreo, do solo, das águas e biocenoses: pesticidas, radonuclidos, metais, hidrocarbonetos policíclicos e em várias outras fontes.

- No desenvolvimento microbiano: toxonas microbianas e micotoxinas.

- Nas operações culinárias e utensílios de cozinha, tais como: produtos de oxidação, polímeros, especialmente resultantes das gorduras, resíduos plásticos e metálicos.

- Nos produtos de migração das embalagens, como: cloreto de vinilo, estireno, vernizes e colas, etc.

- Produtos resultantes das interacções entre aditivos, com outros contaminantes, com os nutrientes do alimento e hipoteticamente com drogas medicamentosas, como por exemplo: as nitrosaminas resultantes de reacções de nitritos com aminas, uretanos da reacção do dietilpirocarbonato com amónia, etc.

- Produtos formados durante o processamento quer pelo calor quer pelas radiações ionizantes, como: o benzopireno e antracenos (resultantes da fumagem), radicais livres, epóxidos, etc.

- Produtos resultantes do envelhecimento durante a armazenagem ou da alteração dos alimentos: furanoterpenos na batata, por exemplo.

- Produtos formados no tubo digestivo pela acção das bactérias: aminas e nitrosaminas, produtos de alteração do triptofano e da metionina.

Quanto à toxicidade que se lhes reconhece é múltipla e oscila entre limites muito vastos. Pode estender-se desde a inocuidade ou muito reduzida até a uma toxicidade aguda e letal, passando por formas tóxicas, leves e indefinidas e por outras de tipo crónico, de sintomatologia muito diversificada, resultantes de bioacumulações por soma de efeitos e mecanismos indirectos. Entre as acçð̄es mais graves destacam-se: alteraçס̄es sanguíneas, efeitos hepatotóxicos, neurotóxicos, embriotóxicos, mutagénicos, teratogénicos, carcinogénícos e alergizantes, entre os muitos que poderiam sr citados.

\section{1. - Intoxicações alimentares agudas}

As castástrofes por razões alimentares de que ainda hoje ouvimos falar resultam da ignorância, da inconsciência, da incompetência, e da ganância do lucro fácil por parte do homem. Basta recordar o caso ocorrido em Espanha, em 1981, com azeite. Dezasseis mil pessoas foram intoxicadas com um sindroma tóxico de pneumonia atípica, vitimando cerca de 350 . E, tudo isto, em consequência de traficantes ávidos de lucro terem tentado, sem conhecimento dos resultados, eliminar por aquecimento do óleo de colza a anilina que lhe servia de revelador para assim o mascararem no azeite. Continuando no cenário de intoxicaçð̃es agudas veiculadas por bleos alimentares, podemos citar as atribuídas ao tricresilfosfato e aos policloretos de bifenilo $\left(\mathrm{PBC}_{\mathrm{S}}\right)$.

- Ao tricresilfosfato, violento neurotóxico, atribui-se a responsabilidade de uma série de intoxicaçð̌es ocorridas, nos Estados Unidos, em 1930, em Marrocos em
1959 e posteriormente em 1977/78 no Ceilāo, tendo sido atingidas vinte mil, duas mil e vinte pessoas, respectivamente. Excepção feita para Marrocos, a intoxicação foi acidental. Deveram-se à contaminação de óleos com plastificantes, de ignifugos e fluídos de sistemas hidráulicos, contendo tricresilfosfato.

- No Japão, em 1968, a contaminação de óleo de arroz com policloretos de difenilo em doses maciças de 2000 e 3000 p.p.m. fez um milhar de vítimas. Posteriormente, em 1979, numa recidiva, mais 1100 pessoas foram atingidas por terem ingerido bleo de arroz preparado por uma unidade industrial que utilizava Kanechlor 400 , um bifenil a $48 \%$, num fluído de permuta de calor.

Neste e noutros domínios da alimentação, o historial da intoxicação aguda é pródigo em exemplos que não cabe exaustivamente relatar. Por isso, por aqui nos quedamos.

\section{2. - Intoxicação alimentar crónica}

Os surtos catastróficos e espectaculares de intoxicação alimentar aguda têm, hoje, reduzido peso na esperança de vida do homem. $\mathrm{O}$ mesmo não se pōe relativamente às possíveis consequências na intoxicação alimentar crónica. A este respeito sabe-se pouco. Acerca dela muito resta por averiguar e saber, mas pensamos ser de grande acuidade.

A toxicidade por bioacumulação, por soma de efeitos e por mecanismos indirectos constituem uma realidade preocupante.

O carácter e a magnitude do risco de qualquer xenobiótico depende das suas características moleculares intrínsecas, dizem respeito ao indivíduo e ao alimento que o veicula e aos teores em que se encontra no alimento, etc.

No domínio da carcinogénese, um dos mais preocupantes da nossa era, várias estruturas merecem atenção: as nitrosaminas, o 4,4' dimetilaminoazobenzeno (amarelo de manteiga), a aflatoxina $\mathbf{B}_{1}$, produzida pelo-(Aspergilus Flavus), os policíclicos aromáticos especialmente o benzo(a) pireno, o cloreto de vinilo e acrilonitrilo que podem contaminar os alimentos por migração das embalagens de plástico, os produtos hormonomiméticos do tipo do dietilestilbestrol (DES) da trembelona e do zeranol empregue nas explorações de animais como anabolizantes, na produção de carne.

Noutros domínios da toxicologia alimentar muitas outras substâncias merecem destaque particular:

- Os resíduos dos produtos cárneos resultantes da utilização de medicámentos veterinários, de antimicrobianos (antibióticos coccidiostácticos) e de anabolizantes que podem ficar nestes produtos se não forem respeitadas as regras. correctas da sua utilização.

- Os pesticidas clorados (DDT, dieldrina, lindano), dos organofosforados e dos carbamatos constituem uma arma perigosa para a saúde e deverão ser controlados dado o uso indiscriminado sobretudo na agricultura.

- As dibenzodioxinas cloradas, especialmente o isómero 2,3,7,8-tetraclorobenzodioxina (TCDD) são portadoras de gravíssima toxicidade devendo rejeitar-se os alimentos que as revelem em teores da ordem dos 50 ppt (partes por trilião).

- Os radionuclidos constituem um problema obscuro entre nós, por não termos equipamento para o seu controlo, mas nem por isso se pode esquecer o seu perigo. 
- Os metais bioacumuláveis, tais como, mercúrio, arsénio, chumbo, cádmio e selénio têm merecido larga prospecção quer a nível dos alimentos quer a nível de embalagens e materiais que com eles normalmente contactam e são responsáveis por sindromas de toxicidade crónica. Nesta matéria, temos larga experiência vivida, quer através dos ensaios realizados sobre os materiais citados (louças, embalagens, trens de cozinha, utensílios industriais, etc.) quer através das análises que exportadores de alimentos enlatados nos vão solicitando. O panorama também aqui não é tranquilizador, se bem que não mais alarmante do que em muitos países.

\section{3. - Tóxicos naturais dos alimentos}

Os resíduos químicos e tóxicos são conotados com os alimentos ditos pré-embalados. A indústria química é a principal responsável. Preferimos os alimentos em "natureza" por serem “guenuínos". Também eu tenho essa preferência. Mas haverá hoje alimentos genuínos? Também não podemos ignorar que os alimentos em natureza são intrinsicamente portadores de tóxicos violentos, já não falando nos que mencionamos e que vão adquirindo ao longo do circuito comercial até nossas casas e aqueles que aqui nós fabricamos mercê de erros que cometemos nas operações culinárias. Vejamos:

\section{1. - Enzimas inibidoras?}

$\mathrm{Na}$ literatura, cereais e legumes indicam-se como contendo inibidores enzimáticos perturbadores do nosso normal processo digestivo. Assim, inibidores trípsicos e quimiotrípsicos têm sido descritos em plantas comestiveis como batata, tomate e amendoim. Inibidores da Amilase, quimicamente glicoproteinas referem-se no Yam ou Inhame, Dioscorea alata muito usada como substituto da batata em muitos países da América do Sul, da África e até na Ilha da Madeira.

No bróculo, no açúcar da beterraba, nos espargos, nas batatas, no rábano, nas cenouras e até nas laranjas e nas maçãs e em tantos outros alimentos têm sido detectados inibidores das colinoesterases.

\section{2. - Lectinas}

Hemaglutininas e lectinas, substâncias da natureza proteica, têm sido referidas em algumas variedades de cultivares de P. vulgaris (feijőes) e soja. Referem-se como depressoras do crescimento e do apetite.

\section{3. - Aminoácidos tóxicos}

A maior luta, do ponto de vista alimentar, que o homem trava com a natureza é para adquirir aminoácidos e sobretudo alimentos ricos nos dez aminoácidos que lhe são essenciais.

Todavia, há alguns aminoácidos produzidos por plantas e que lhe são tóxicos, como por exemplo, o oxalil $\mathbf{L} \alpha, \beta, \gamma$ diaminobutírico e propiónico isolado do $\mathbf{L}$. sativus.

Outros, como a hipoglicina, a mimosina, a selenocisteína e a selenocistina são também deletérios.

\section{4. - Lípidos tóxicos}

Os lípidos fazem parte da dieta humana, cabendo-lhes uma quota de $20 \%$ a $30 \%$ das necessidades energéticas diárias.

Porém, óleos derivados de algumas Crucíferas, Brassica spp., tais como, o óleo de colza e de mostarda contêm ácidos gordos de efeitos tóxicos: ácido erúcico ou 13-cisdocosenoico $\left(C_{22: 1}\right)$ e 11-eicosenoico $\left(C_{20: 1}\right)$.

$\mathrm{Na}$ sintomatologia tóxica incluem-se: alteraçð̄es cardíacas, adrenais e hepáticas e atraso de crescimento em animais de experiência.

O óleo de colza é consumido por milhões de pessoas, particularmente asiáticos. Nś também vamos ter que consumi-lo quer queiramos quer não e num futuro próximo. Acreditamos que os teores do ácido citado não excedam mais de $5 \%$ dos ácidos totais dos óleos alimentares, tal como a lei comunitária estipula.

\section{5. - Carcinógenos e alergenos naturais}

Carcinógenos e alergenos nos alimentos "em natureza" também os há.

\subsection{1. - Carcinógenos ou procarcinógenos}

Aos glucosinolatos do óleo de colza e a goitrina (5-Viniloxazolidina-2-tiona) das Crucíferas (mostarda, repolho, nabiças, etc.) são atribuídas acções carcinogenéticas.

A goitrina inibe a incorporação do iodo nos precursores da hormona da tiroide conducentes à tiroxina, provocando hiperplasia e hipertrofia da glândola tiroide. Às aglíconas dos glucosinolatos, geradores de tiocianeto e isotiocianato associam-se efeitos neurológicos.

\subsection{2. - Alergenos}

Há alimentos que manifestam mais frequentemente acções alergizantes do que outros, Estão neste caso: o leite, o cacau, o chocolate, os morangos, o trigo, etc. Urticária, rinites, asma, cefalalgia, conjuntivites, inflamações articulares, inflamaçð̃es vesiculares e irritabilidade é todo um quadro sintomatológico bem conhecido dos médicos alergologistas e frequentemente com etiologia alimentar.

Estes efeitos estão particularmente conotados com histamina e outras aminas e também com glicoproteínas, com o glúten (caso do trigo), dos alimentos citados. As notas que aqui deixamos constituem uma pequena amostragem da vastidão do tema dos tóxicos alimentares. o leitor interessado poderá preencher as lacunas e ampliar os conhecimentos nesta temática consultando a bibliografia indicada [1-5].

\section{BIBLIOGRAFIA}

[1] E.M. Boyd, Toxicity of Pure Foods, CRC Press, 1976.

[2] I.E. Liener, Toxic nstituents of Plant Foodstuffs, Academic Press, 1969.

[3] I.E. Liener, Toxic Constituents of Animal Foodstuffs, Academic Press, 1974.

[4] J. Gilbert, Analysis of Food Contaminants, Elsevier Applied Science Publisters, 1984.

[5] J.V. McLoughlin e B.M. McKenna, Foods Science and Human Welfare, Volume 4, Proceedings of the Sixth International Congress of Food Science and Technology, Boole Press, Dublin, 1983. 
PRODUTOS E EQUIPAMENTOS PARA A INDÚSTRIA E LABORATORIOS LDA

DINAMISMO - QUALIDADE - SERVIÇO

\section{ESCOLHA - EFICIÊNCIA}

PEÇA-NOS A LISTA DAS NOSSAS REPRESENTADAS

ALGUMA LHE INTERESSARÁ!

Estamos à distância do seu telefone...

QUINTA DA PIEDADE, LOTE $12-1 .^{\circ}$

\section{COLABORE COM A SOCIEDADE}

\section{NÃO ATRASE \\ O PAGAMENTO \\ DAS \\ SUAS QUOTAS}

